\title{
Passive Cooling of Building using Glycerine and Paraffin Wax with Perlite as Phase Changing Materials
}

\author{
Dr. P. Kathirvel, Dr. R. Lakshmi \\ Professor / Civil Engineering \\ Kamaraj College of Engineering and Technology \\ Madurai - 625701, India.
}

\author{
M. Ahamed Ibrahimsha, A. Gowri Sankar, \\ E. Karthick Siva, P. S. Poorna Prakash \\ Former UG Students \\ Kamaraj College of Engineering and Technology \\ Madurai - 625701, India.
}

\begin{abstract}
The exponential increase in population growth has led to increase in high consumption of natural resources, which directly and indirectly is the source of liberation of $\mathrm{CO}_{2}$ in the atmosphere. Along with the construction industry, which is also a major source of liberation of greenhouse gases, active cooling devices such as the air conditioners $\&$ refrigerators also become the major source of emission of greenhouse gases. In order to control the room temperature by passive method, Phase Changing Materials (PCM) can be used in buildings. PCMs or latent heat storage materials are generally materials with large specific latent heat capacity. PCMs used in buildings will typically melt and solidify within a range of $18-30^{\circ} \mathrm{C}$ and are normally integrated in the building fabric. They can be used in the built environment to reduce internal temperature change by storing latent heat in the solid-liquid or liquid-gas phase change of a material. PCMs are found to store 5 to 14 times more thermal energy per unit volume than conventional thermal storage materials. The main objective of this project is to obtain ambient temperature within buildings and to reduce the usage of the active cooling machineries which releases greenhouse gases responsible for earth's temperature rise. Telkes and Tyaghiare the first researchers, who have undertaken the work on application of PCMs in buildings in $\mathbf{1 9 7 5}$ and concluded that they can be incorporated with ordinary building materials. Organic PCMs like Paraffin wax and Glycerine are used and infiltrated with cement mortar. To prevent the leakage of these PCMs Perlite is used. The objective of the present work is to study the effects of various types of PCM including Glycerine, Paraffin wax and Perlite with Paraffin wax in control of the room temperature from mortar plastered brick masonry model and comparing the results by simulating in software.
\end{abstract}

Keywords-Phase change materials; passive cooling in building; paraffin wax; glycerine; perlite

\section{INTRODUCTION}

The major causes of global warming are by Carbon dioxide $\left(\mathrm{CO}_{2}\right)$ which is an important greenhouse gas released through human actions such as burning fossil fuels and deforestation, as well as natural processes such as respiration and upsurge of volcanoes. It is expected that an increase of $+1^{\circ} \mathrm{C}$ of room temperature In years. PCM is a material with a high heat of fusion which, melting and solidifying at a certain temperature, is capable of storing and discharging large quantities of energy. When the outside temperature is more than ambient temperature, the PCM changes to liquid phase and prevents the entry of heat inside. When the outside temperature is less than ambient temperature, the PCM changes to solid phase and prevents the entry of heat inside. The Phase change materials are basically classified into two types, namely Organic PCM and Inorganic PCM. The organic PCMs are naturally available materials such as Lauric acid, Paraffin Carbons, Formic acid, Glycerine, which are safe, stable, freeze at lesser drop in temperature and are recyclable. However they have low thermal conductivity in their solid state and are most costly. The Inorganic PCMs such as Sodium sulphate, sodium chloride, Aluminium, Gold, Copper, Silver, Titanium, etc. are chemicals which have high volumetric latent heat storage capacity, sharp melting point, high thermal conductivity and are relatively low cost. However their change of volume is very high and often become defective after in due course.

The study of A.Yahaya et.al. (2011) showed that the application of PCM slab panels could effectively reduce the energy consumption through active cooling systems. Application of PCM wallboards in building delivers latent heat storage throughout the building envelope (Arash Bastani et.al, 2015). The incorporation of a PCM layer into an external building wall reduced the magnitude of the sudden heat flux through the wall (Necib Hichemet.al, 2013). An evaluation of a brick with and without PCM showed a temperature difference of $3.78^{\circ} \mathrm{C}$. Concrete prepared with $10 \%, 15 \%$, and $20 \%$ of paraffin wax which has melting point $26^{\circ} \mathrm{C}$, showed upto $20 \%$ much lower temperature than the blank sample. The temperature difference value is about $3.6^{\circ} \mathrm{C}$ in heating condition and is about $2.4^{\circ} \mathrm{C}$ in cooling condition (Qing Wang et.al, 2012). Perlite, diatomite, expanded graphite, and silica fume are commonly used with PCM to prevent leakage and to attain the required strength (Huiqiang Li et.al,2014). Highest Compressive Strength was obtained while mixing the Paraffin wax and the hydrophobic fumed silica in Cement Mortar where leakage of paraffin can be prevented by adding hydrophobic fumed silica, PCMs may increase the thermal mass of lightweight buildings and then equalize the indoor temperature swings by which peak load flowing could be achieved (Guobing Zhou, et.al, 2011). The simulations, carried out in PCM wallboards, showed a potential reduction of $2^{\circ} \mathrm{C}$ in the peak indoor air temperature (G. Evola, et.al, 2013). The heat flux at the indoor space can be reduced by $17.55 \%$ when three PCM cylinders are introduced placed at the centre line of bricks (Esam M. 
Alawadhi, et.al, 2008). PCM in conventional and alveolar brick construction reduced the energy consumption compared with the same cubicle without PCM (A. Castell, et.al, 2010).

The use of PCM in brick walls is helpful for the thermal insulation, temperature hysteresis and thermal comfort for occupants (Chengbin Zhang, et.al, 2011). Compared to a brick wall, Gypsum board with $45 \%$ PCMs stores five times more energy per unit mass, 9.5 times more energy and about three times more energy per unit mass than a ordinary gypsum board (Alicia Oliver et.al, 2012). The thermal amplitude is decreased in the interior domain with the increase of the PCM thickness. The model with the larger PCM thickness of $25 \mathrm{~mm}$ reduces about 22\% (Tiago Silva, et.al, 2012). PCM used is able to absorb the heat developing from the external thermal conditions, thereby changing its phase from solid to liquid. During the night time the PCM solidifies and releases the stored heat. The application of PCM led to a delay of about six hours in the heat flux peak, and a reduction of 25\% (Paolo Principi, et.al, 2012). A thermal analysis of a building concrete roof with vertical cylindrical holes filled with PCM showed that the heat flux at the indoor surface of the roof can be reduced between $12.04 \%$ and $17.26 \%$ depending on the operating month (Hashem.J.Alqallaf, et.al, 2013). PCM in perforated brick rooms produced result with good effect of decreasing temperature peak $\left(1^{\circ} \mathrm{C}\right.$ to $\left.2.3^{\circ} \mathrm{C}\right)$, reducing temperature fluctuation and increasing the thermal inertia, and indicated the opportunity of PCM panel usage (Xiangfei Kong, Shilei Lu, et.al, 2013). The use of silver nanoparticles in PCM Paraffin wax enhances the ability of thermal energy storage of the materials. (Pradeep.N.et.al, 2020). From the review of literature, the most widely used PCM is Paraffin wax. PCMs have a better temperature control while adding in cement mortar and plastering. Perlite prevents the leakage of PCM during exposing condition. Other PCMs (such as Glycerine) can also be used in effective temperature control.

\section{MATERIALS AND METHODS}

\section{A. Material Collection and Model Preparation}

Four numbers of brick masonry room models were prepared (Fig.1(a),(b),(c)) with inner size $600 \mathrm{~mm} \times 600 \mathrm{~mm} \times$ $600 \mathrm{~mm}$, covered by Reinforced Cement Concrete (RCC) slab of size $600 \mathrm{~mm} \times 600 \mathrm{~mm} \times 75 \mathrm{~mm}$ M20 grade concrete with reinforcement $6 \mathrm{~mm} @ 150 \mathrm{~mm}$ c/c both ways. The walls were make of red brick $150 \mathrm{~mm}$ thick with mortar and plastering by Cement Mortar (CM) 1:5 mix. A small opening of size $150 \mathrm{~mm} \times 150 \mathrm{~mm}$ was provided on one wall to enable the study of temperature inside the room at regular intervals.
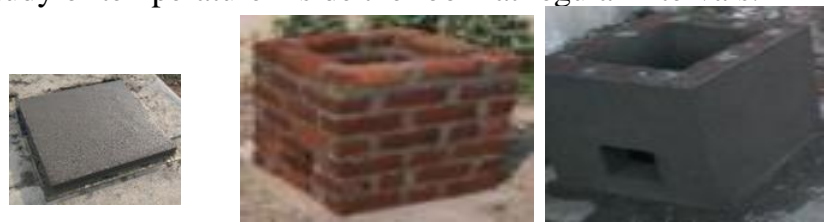

Fig.1 (a) Cover slab; (b) Prototype brick work; (c) Prototype wall plastered

The variation in the four models were the PCMs used in the cement mortar used between the bricks, inner and outer wall plaster. The PCMs used in the three models were 5\% Glycerine, 5\% Paraffin wax and 5\% Paraffin wax with Perlite, the results of which were compared with the control mix of only cement mortar used. The four mixes are given in Table 1 .

TABLE 1 - Mix Proportions

\begin{tabular}{|l|l|l|l|}
\hline S.No. & Mix ID & Cement Mortar & PCM (by weight of Cement) \\
\hline 1 & CM & $1: 5$ & - \\
\hline 2 & CMG & $1: 5$ & $5 \%$ Glycerine \\
\hline 3 & CMP & $1: 5$ & $5 \%$ Paraffin Wax \\
\hline 4 & CMPP & $1: 5$ & $5 \%$ Paraffin Wax $+5 \%$ Perlite \\
\hline
\end{tabular}

The temperature variation in the four prototype models were studied for 30 days during morning, afternoon and evening. The temperature readings were taken through using industrial temperature sensor for 12 hours per day. Also to find the thermal variation in the prototype ANSYS modelling software was used to model the thermal variation of the four models with the same materials and dimensions and plotted to get the 2D Thermal Variation of Brick, as shown in Fig.2.

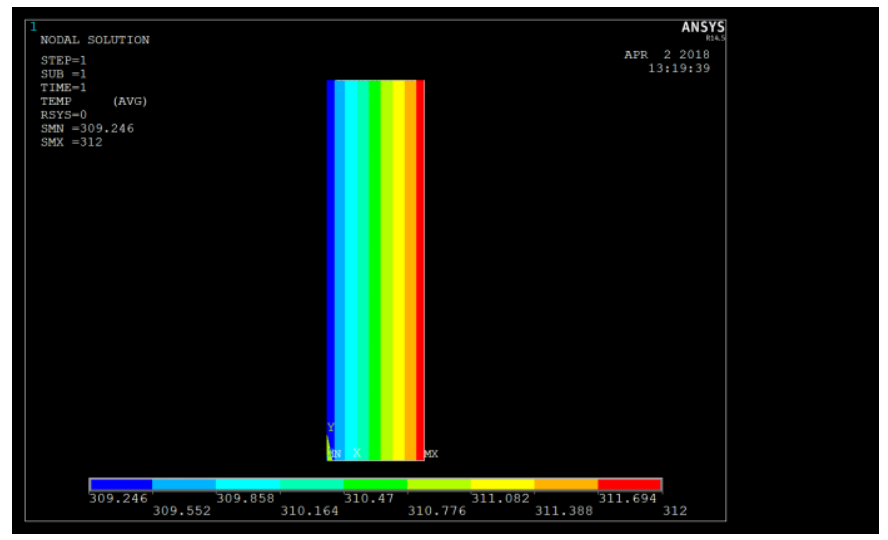

Fig.2 Two Dimensional Pattern of Wall brick done using ANSYS software

\section{B. Physical properties Test}

The specific gravity of the raw materials including cement, fine aggregate and coarse aggregate were found as per standards, as 3.15, 2.65 and 2.65 respectively. The four mix proportions of cement mortar were tested for water absorption. The compressive strength of the mortar mixes were arrived as per IS 4031-1988(Part 6). To find the coefficient of thermal conductivity of a cement mortar with different proportions using Lee's Disc Apparatus. The thermal conductivity was calculated by using Equation 1.

$\mathrm{K}=\quad\left(\mathbf{M s d} *(\mathbf{r}+\mathbf{2 h}) *(\mathbf{d \theta} / \mathbf{d t}) * \boldsymbol{\theta}_{2} / \boldsymbol{\pi} \mathbf{r}^{2} *\left(\boldsymbol{\theta}_{1}-\boldsymbol{\theta}_{2}\right) *(\mathbf{2 r}+\mathbf{h})\right) \quad \mathbf{W} / \mathbf{m} / \mathrm{k}$

(1)

where, M- Mass of the metal disc in $\mathrm{kg}$

$\mathrm{s}-$ Specific heat capacity of the material of disc in $\mathrm{Jkg}^{-1} \mathrm{~K}^{-1}$

$\mathrm{d}$ - Thickness of a bad conductor in $\mathrm{m}$

$\mathrm{r}$ - Radius of the metallic disc in $\mathrm{m}$

$\mathrm{h}$ - Thickness of the metal disc in $\mathrm{m}$

$\boldsymbol{\theta} 1$ - steady state temperature of the steam chamber ${ }^{\circ} \mathrm{C}$ $\boldsymbol{\theta 2}$ - steady state temperature of the metal disc in ${ }^{\circ} \mathrm{C}$ temperature $\mathbf{d \theta} / \mathbf{d t}$ - rate of cooling at steady state

\section{RESULTS AND DISCUSSION}

The results of the compressive strength test, thermal conductivity test for the four mixes in the models have been tabulated below. 
A. Compressive Strength Test

The compressive strength of the mixes added with PCM showed lesser results than the control mortar mix CM. However the strength of mortar in brick and plastering is immaterial when the brick walls are used in framed buildings and non-load bearing walls.

TABLE 2 - Compressive Strength Test
\begin{tabular}{|l|l|c|}
\hline $\begin{array}{l}\text { S. } \\
\text { No. }\end{array}$ & Mix ID & $\begin{array}{l}\text { Compressive } \\
\text { Strength }\left(\mathrm{N} / \mathrm{mm}^{2}\right)\end{array}$ \\
\hline 1 & CM & 9.61 \\
\hline 2 & CMG & 3.98 \\
\hline 3 & CMP & 3.71 \\
\hline 4 & CMPP & 4.50 \\
\hline
\end{tabular}

\section{B. Water Absorption Test}

The water absorption test from Table 3 also showed results similar to the compressive strength test where the absorption increased for the mortar mixes with PCMs but were within the limits.

TABLE 3 - Water Absorption Test
\begin{tabular}{|l|l|l|}
\hline $\begin{array}{l}\text { S. } \\
\text { No. }\end{array}$ & Mix ID & $\begin{array}{l}\text { Water } \\
(\%)\end{array}$ \\
\hline 1 & CM & 1.23 \\
\hline 2 & CMG & 1.29 \\
\hline 3 & CMP & 2.70 \\
\hline 4 & CMPP & 2.78 \\
\hline
\end{tabular}

\section{Thermal Conductivity Test (Lee's Disc Apparatus)}

Table 4 shows the results of the thermal conductivity value, in this CMPP shows the lowest value of all others. High thermal conductivity are generally used in heat drop applications and the materials of low thermal conductivity are used as thermal insulation.

TABLE 4 - Thermal Conductivity Test
\begin{tabular}{|l|l|l|}
\hline $\begin{array}{l}\text { S. } \\
\text { No. }\end{array}$ & Mix ID & $\begin{array}{l}\text { Thermal } \\
(\mathrm{W} / \mathrm{m} / \mathrm{k})\end{array}$ \\
\hline 1 & CM & 0.52 \\
\hline 2 & CMG & 0.68 \\
\hline 3 & CMP & 0.44 \\
\hline 4 & CMPP & 0.39 \\
\hline
\end{tabular}

D. Temperature variation of outside, $C M$ and $C M G$ mixes

The variation of temperatures is shown in a graph for respective 12 hours timely readings. The Fig. 3 shows the average temperature between outside temperature and $\mathrm{CM}$ without PCM and CMG. The CMG was found to give the better results with reduction in temperature of $3 \%$ during day time and increase in temperature of $3 \%$ during night time.

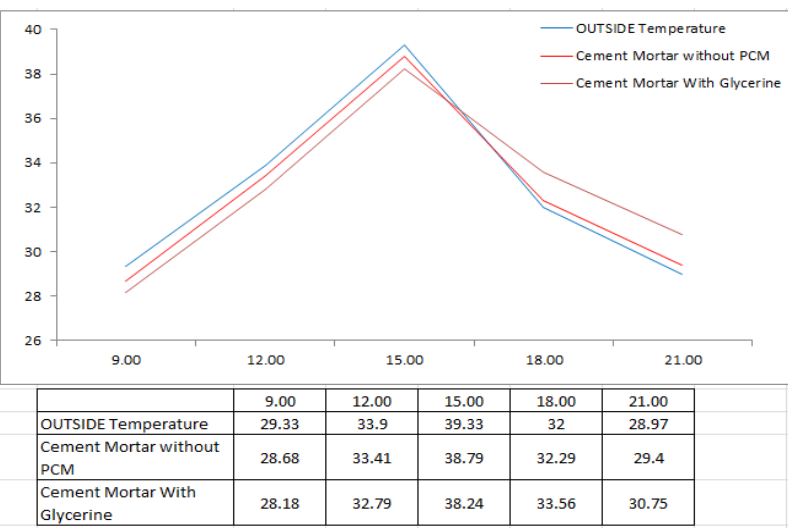

Fig. 3 Temperature variation of outside, $\mathrm{CM}$ and $\mathrm{CMG}$ mixes
E. Temperature variation of outside, CM and CMP mixes

The Fig.4 shows the average temperature between outside temperature and CM without PCM and CMP. The CMP was found to give reduction in temperature of $2 \%$ during day time and increase in temperature of $2 \%$ during night time.

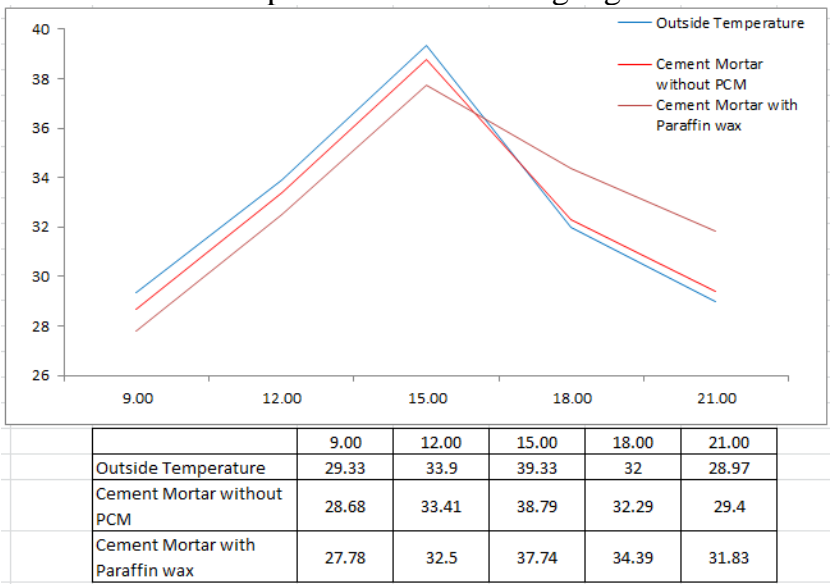

Fig.4 Temperature variation of outside, CM and CMP mixes

F. Temperature variation of outside, CM and CMPP mixes

Fig.5 shows the average temperature between Outside temperature, CM without PCM and CMPP. The CMPP was found to give the better results with reduction in temperature of $5 \%$ during day time and increase in temperature of $5 \%$ during night time.

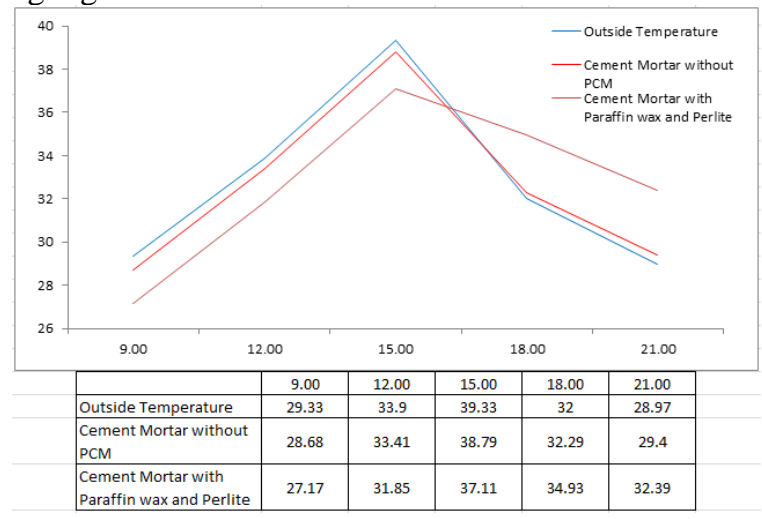

Fig.5 Temperature variation of outside, CM and CMPP mixes

\section{G. Thermal variation from ANSYS of CM with PCMs for four} mixes at 9 am

To find the temperature reduction in each of the Model wall bricks from Outside Surface to Inner Surface a two dimensional analysis of brick with $\mathrm{CM}$ and PCM were modelled and analyzed using ANSYS software. These kinds of analysis were done and visualized the heat flux with all mixed proportions. Fig.6 shows the thermal conductivity results outside and inside the wall at 9am for the four mixes. It is seen from the graph that CMPP shows the best thermal insulation. 


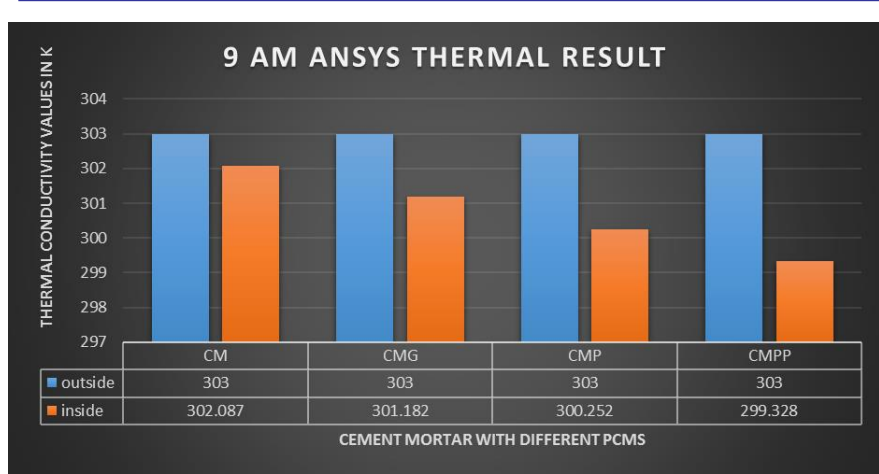

Fig.6 Thermal variation from ANSYS of CM with PCMs for four mixes at $9 \mathrm{am}$

\section{H. Thermal variation from ANSYS of CM with PCMs for four} mixes at 12 noon.

Fig.7 shows the thermal variation analysed by Ansys software for $12 \mathrm{pm}$. In this the forth composition with paraffin and perlite shows the best thermal insulation for $12 \mathrm{pm}$.

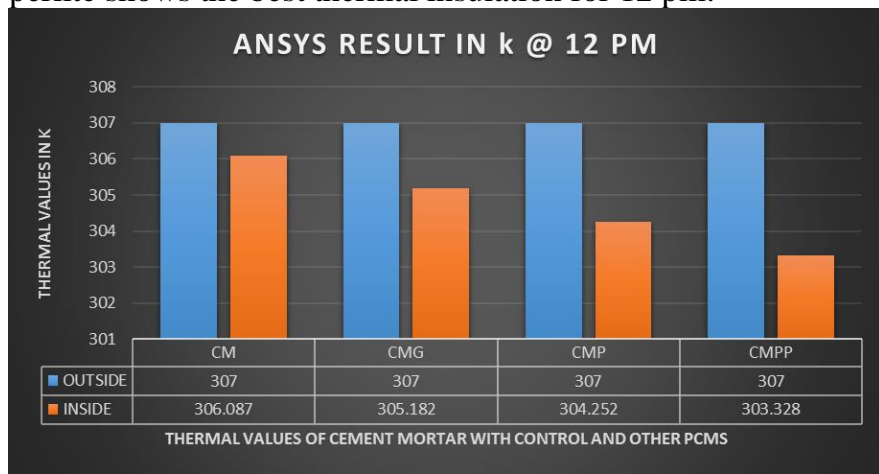

Fig.7 Thermal variation from ANSYS of CM with PCMs for four mixes at 12 noon

\section{Thermal variation from ANSYS of CM with PCMs for four} mixes at $3 p m$

Fig. 8 shows the thermal variation analysed by Ansys software for $3 \mathrm{pm}$. In this the forth composition with paraffin and perlite shows the best thermal insulation for $3 \mathrm{pm}$.

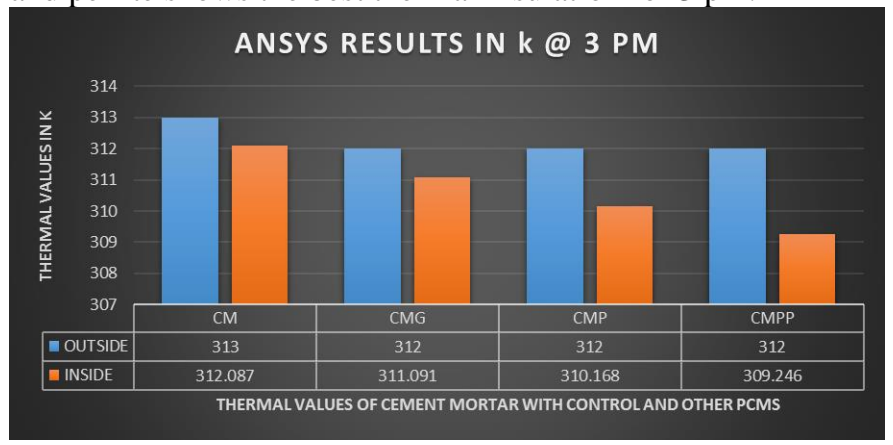

Fig.8 Thermal variation from ANSYS of CM with PCMs for four mixes at $3 \mathrm{pm}$

\section{J. Thermal variation from ANSYS of CM with PCMs for four} mixes at $6 \mathrm{pm}$

Fig.9 shows the thermal variation analysed by Ansys software for $6 \mathrm{pm}$. In this the forth composition with paraffin and perlite shows the best in maintaining the ambient temperature during very cold period for $6 \mathrm{pm}$.

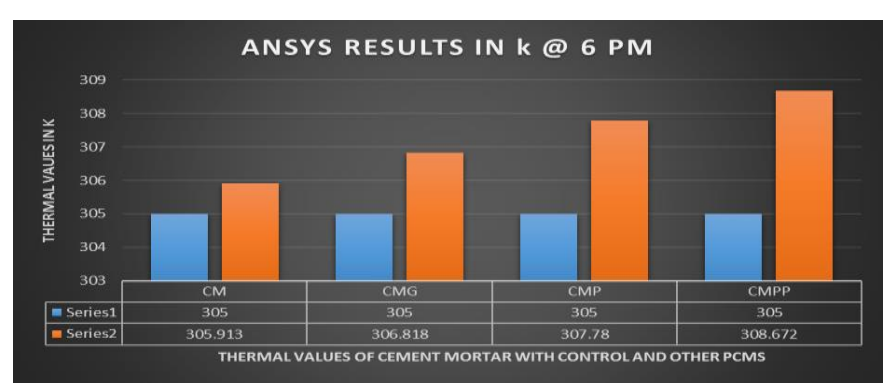

Fig.9 Thermal variation from ANSYS of CM with PCMs for four mixes at $6 \mathrm{pm}$

\section{K. Thermal variation from ANSYS of CM with PCMs for four} mixes at $9 p m$

The above graph shows the thermal variation analysed by Ansys software for $9 \mathrm{pm}$. In this the forth composition with paraffin and perlite shows the best in maintaining the ambient temperature during very cold period for $9 \mathrm{pm}$.

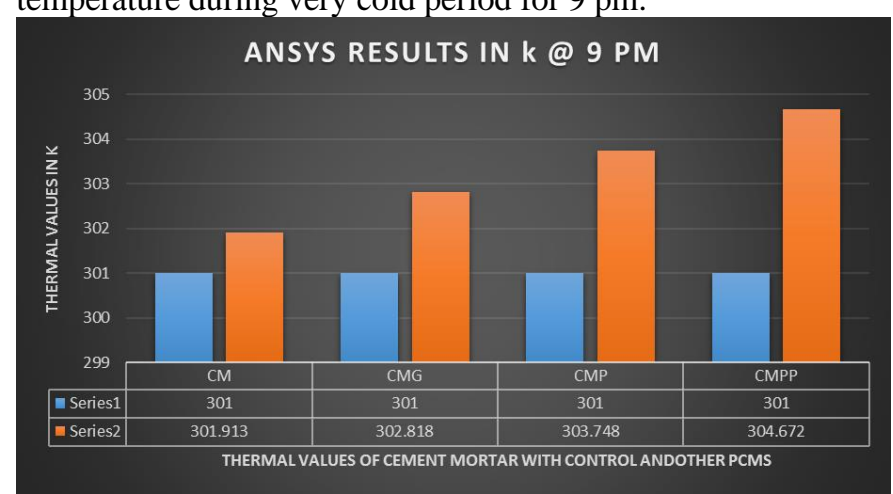

Fig.10 Thermal variation from ANSYS of CM with PCMs for four mixes at $9 \mathrm{pm}$

\section{CONCLUSION}

The three PCM mixes proved to perform well in regulating the temperature within the prototype building. The CMPP mix with 5\% paraffin and 5\% perlite was found to control the temperature by $5 \%$ both during day and night, which can be effectively used as a passive air conditioning method in buildings. Though the strength of the mortar mix reduces compared to the control mix, it does not have impact on the brick masonry walls owing to the usage of non-load bearing walls in framed structures, which are the most adopted method of construction these days.

\section{REFERENCES}

[1] Alicia Oliver et.al, "Thermal characterization of gypsum boards with PCM included: Thermal energy storage in buildings through latent heat", Energy and Buildings vol.48, pp-1-7, 2012.

[2] Arash Bastani et.al, "Investigating the effect of control strategy on the shift of energy consumption in a building integrated with PCM wallboard", Energy Procedia, vol. 78, pp-2280 - 2285, 2015.

[3] A. Castell, et.al, "Experimental study of using PCM in brick constructive solutions for passive cooling" Energy and Buildings vol.42, pp-534-540, 2010.

[4] Chengbin Zhang, et.al, "Thermal response of brick wall filled with phase change materials (PCM) under fluctuating outdoor temperatures", Energy and Buildings vol.43, pp-3514-3520, 2011.

[5] Esam M. Alawadhi, et.al, "Thermal analysis of a building brick containing phase change material", Energy and Buildings vol.40, pp351-357, 2008

[6] G. Evola, et.al, "A methodology for investigating the effectiveness of PCM wallboards for summer thermal comfort in buildings", Building and Environment vol.59, pp-517-527, 2013. 
[7] Guobing Zhou, et.al "Performance of shape-stabilized phase change material wallboard with periodical outside heat flux waves", Applied Energy vol.88, pp-2113-2121, 2011.

[8] Hashem J. Alqallaf, et.al, "Concrete roof with cylindrical holes containing PCM to reduce the heat gain", Energy and Buildings vol.61, pp-73-80, 2013.

[9] Huiqiang Li et.al, "Development of thermal energy storage composites and prevention of PCM leakage", Applied Energy vol.135, pp-225-233, 2014.

[10] Necib Hichem et.al, "Experimental and numerical study of a usual brick filled with PCM to improve the thermal inertia of buildings", Energy Procedia, vol. 36, pp-766 - 775, 2013.

[11] Paolo Principi, et.al, "Thermal analysis of the application of PCM and low emissivity coating in hollow bricks", Energy and Buildings vol.51, pp-131-142, 2012
[12] Qing Wang et.al, "Study on Properties of Paraffin Phase Change Energy Storage Concrete", Energy Procedia, vol.16, pp-365 - 370, 2012.

[13] Tiago Silva, et.al, "Experimental testing and numerical modelling of masonry wall solution with PCM incorporation: A passive construction solution", Energy and Buildings vol.49, pp-235-245, 2012.

[14] Xiangfei Kong, Shilei Lu, et.al, "Experimental research on the use of phase change materials in perforated brick rooms for cooling storage", Energy and Buildings vol.62, pp-597-604, 2013.

[15] N. A. Yahaya et.al, "Numerical Investigation of Indoor Air Temperature with the Application of PCM Gypsum Board as Ceiling Panels in Buildings", Procedia Engineering, vol.20, pp-238 - 248, 2011.

[16] Pradeep.N., Paramasivam.K., Rajesh.T., Subash Purusothamanan.V., Iyahraja.S., "Silver nanoparticles for enhanced thermal energy storage of phase change materials", Materials Today (In Press), 17 March 2020 . 